\title{
A UNIFIED MODEL FOR TERRESTRIAL RARE GASES
}

\author{
D. Porcelli and G.J. Wasserburg \\ The Lunatic Asylum of the Charles Arms Laboratory \\ Division of Geological and Planetary Sciences \\ California Institute of Technology, Pasadena, CA 91125
}

\begin{abstract}
A steady state upper mantle model for the rare gases has been constructed which explains the available observational data of mantle $\mathrm{He}, \mathrm{Ne}, \mathrm{Ar}$, and $\mathrm{Xe}$ isotope compositions and provides specific predictions regarding the rare gas isotopic compositions of the lower mantle, subduction of rare gases, and mantle rare gas concentrations. The model incorporates two mantle reservoirs; an undegassed lower mantle (P) and a highly degassed upper mantle (D). Chemical species are transferred into D within mass flows from $\mathrm{P}$ at plumes and from the atmosphere by subduction. Rare gases in D are derived from mixing of these inflows with radiogenic nuclides produced in situ. The upper mantle is degassed at mid-ocean ridges and hotspots. Flows of each isotope into D are balanced by flows out of D, so that upper mantle concentrations are in steady state. Rare gases with distinct ${ }^{3} \mathrm{He} /{ }^{4} \mathrm{He}$, ${ }^{20} \mathrm{Ne} /{ }^{22} \mathrm{Ne},{ }^{129} \mathrm{Xe} /{ }^{130} \mathrm{Xe}$, and ${ }^{136} \mathrm{Xe} /{ }^{130} \mathrm{Xe}$ are stored in $\mathrm{P}$ and are transferred into $\mathrm{D}$. In $\mathrm{P}$, isotopic shifts are due to decay of $\mathrm{U}$ - and $\mathrm{Th}$ - decay series nuclides, ${ }^{40} \mathrm{~K},{ }^{129} \mathrm{I}$, and ${ }^{244} \mathrm{Pu}$ over $4.5 \mathrm{Ga}$. Radiogenic ${ }^{136} \mathrm{Xe}$ in $\mathrm{P}$ is dominantly from ${ }^{244} \mathrm{Pu}$. In the well-outgassed $\mathrm{D}$ reservoir, additional isotopic shifts are due to decay of $\mathrm{U}$ - and Th- series nuclides and ${ }^{40} \mathrm{~K}$ over a residence time of $\sim 1.4 \mathrm{Ga}$. Since ${ }^{4} \mathrm{He},{ }^{21} \mathrm{Ne}$,

${ }^{40} \mathrm{Ar}$, and ${ }^{136} \mathrm{Xe}$ are produced in proportions fixed by nuclear parameters, the resulting isotopic shifts are correlated. The model predicts that the shift in ${ }^{21} \mathrm{Ne} /{ }^{22} \mathrm{Ne}$ in $\mathrm{D}$ relative to that in $\mathrm{P}$ is the same as that for ${ }^{4} \mathrm{He} /{ }^{3} \mathrm{He}$ in the respective mantle reservoirs. This is compatible with the available data for MORB and hotspots. The minimum ${ }^{40} \mathrm{Ar} /{ }^{36} \mathrm{Ar},{ }^{129} \mathrm{Xe} /{ }^{130} \mathrm{Xe}$, and ${ }^{136} \mathrm{Xe} /{ }^{130} \mathrm{Xe}$ ratios in $\mathrm{P}$ are found to be substantially greater than the atmospheric ratios. The range in $\mathrm{Ne}, \mathrm{Ar}$, and $\mathrm{Xe}$ isotopes measured in MORB are interpreted as reflecting contamination of mantle rare gases by variable proportions of atmospheric rare gases. Subduction is not significant for $\mathrm{He}$ and $\mathrm{Ne}$, but may account for a substantial fraction of $\mathrm{Ar}$ and $\mathrm{Xe}$ in $\mathrm{D}$. The rare gas relative abundances in $\mathrm{P}$ are different than that of the atmosphere and are consistent with possible early solar system reservoirs as found in meteorites. The ${ }^{3} \mathrm{He} /{ }^{22} \mathrm{Ne}$ and ${ }^{20} \mathrm{Ne} /{ }^{36} \mathrm{Ar}$ ratios of $\mathrm{P}$ are within the range for meteorites with 'solar' $\mathrm{Ne}$ isotope compositions. The ${ }^{130} \mathrm{Xe} /{ }^{36} \mathrm{Ar}$ ratio of the lower mantle is greater than that of the atmosphere, and may be as high as the ratio found for meteoritic 'planetary' rare gases.

In the model, atmospheric rare gas isotope compositions are distinct from those of the mantle. If the Earth originally had uniform concentrations of rare gases, degassing of the upper mantle would have provided only a small proportion of the nonradiogenic rare gases presently in the atmosphere. The remainder was derived from late-accreted material with higher concentrations of rare gases. However, radiogenic ${ }^{129} \mathrm{Xe}$ and ${ }^{136} \mathrm{Xe}$ abundances imply a substantial loss of rare gases up to $\sim 10^{8}$ years after meteorite formation either from the early Earth or from late-accreting protoplanetary materials. Rare gases must have been lost during accretion and the moon-forming impact, so that nonradiogenic rare gases in the atmosphere must have been supplied by subsequently accreted material with nonradiogenic Xe, possibly from comets. Fractionation of atmospheric Xe isotopes relative to other early solar system components occurred either on late-accreting materials or during loss from the Earth.
\end{abstract}

\section{INTRODUCTION}

Brown ${ }^{1}$ originally argued that volatiles at the surface are derived from outgassing of the solid Earth, and subsequent measurements of isotopically distinctive $\mathrm{He}^{2-5}, \mathrm{Ne}^{6-9}$, and $\mathrm{Xe}^{10,11}$ in terrestrial materials unambiguously document that nuclides originally trapped or formed early within the Earth continue to outgas. Models of the distribution of volatiles and the processes of outgassing have 
continued to evolve. Early models for the evolution of Ar isotopes postulated degassing of a single mantle reservoir to produce the atmosphere, with mantle Ar representing the residue of this process ${ }^{12,13}$. Based upon measurements of Ar in hotspot volcanics that were substantially less radiogenic than $\mathrm{Ar}$ in mid-ocean ridge basalts, Hart et al. ${ }^{14}$ postulated that two mantle reservoirs evolved in an Earth originally uniform in Ar concentration; a primitive undegassed lower mantle sampled at hotspots and an upper mantle sampled by mid-ocean ridge basalts (MORB) which has served as the source of the atmosphere. This scheme followed models of crustal extraction from a limited portion of the mantle based upon $\mathrm{Nd}$ and $\mathrm{Sr}$ isotope studies ${ }^{15,16}$. Allegre et al. ${ }^{17,18}$ have refined and extended the model to include all of the rare gases. The essential features of their model are: a) an Earth initially uniform in rare gas isotope compositions and concentrations; b) an upper mantle that has largely degassed early to form the atmosphere, so that subsequent in situ radiogenic production in the upper mantle has produced radiogenic rare gas isotope compositions; c) no other sources or losses of atmospheric rare gases, so that the atmosphere plus upper mantle has concentrations of all isotopes equal to those of the bulk Earth; d) a closed system lower mantle with high ${ }^{3} \mathrm{He} /{ }^{4} \mathrm{He}$ ratios as measured in ocean island basalts (OIB) and with bulk Earth concentrations of other rare gases, including radiogenic isotopes; and e) no subduction of rare gases or interaction between mantle reservoirs. Since the upper mantle is highly outgassed, the atmosphere-upper mantle system has approximately atmospheric rare gas isotope compositions. Measured $\mathrm{Ar}$ and Xe from OIB with atmospheric compositions were interpreted as representing the lower mantle reservoir, and confirming atmospheric bulk Earth ratios. Although Staudacher and Allegre ${ }^{11}$ originally interpreted the ${ }^{136} \mathrm{Xe}$ excesses measured in MORB as due to the decay of ${ }^{244} \mathrm{Pu}$, this was subsequently reinterpreted as due to the decay of ${ }^{238} \mathrm{U}^{18}$ and the possible role of ${ }^{244} \mathrm{Pu}$ was not incorporated into their model. This model appeared successful at explaining the data available at that time.

As additional data has been acquired, objections to the above model have been raised:

1. Variations in ${ }^{20} \mathrm{Ne}^{22} \mathrm{Ne}$ ratios in mantle-derived materials have been found which cannot be ascribed to additions by nuclear processes and require a mantle component with a Ne isotope composition that is fundamentally different from that of the atmosphere $e^{6-9}$. The difference between the reservoirs may be due to initial heterogeneity in $\mathrm{Ne}$ or Ne losses from the atmosphere involving major fractionation. Both of these scenarios are at odds with an assumed uniform and closed system Earth.

2. The distinctive upper mantle $\mathrm{Ne}$ and Xe isotopic ratios must have been established early in Earth history. However, it is difficult to maintain these characteristics in a highly depleted reservoir underlain by an undegassed reservoir. The continuing rise of plumes through the upper mantle would be expected to contaminate the upper mantle signature ${ }^{19}$.

3. Accretionary models of planetary formation imply substantial losses of rare gases in the atmosphere, both by 'atmospheric erosion, ${ }^{20}$ and by the moon-forming impact ${ }^{21,22}$. In addition, the nonradiogenic Xe isotopes in the atmosphere are highly fractionated with respect to other solar system components, and it has been hypothesized that this is due to hydrodynamic losses from the atmosphere ${ }^{23,24}$. Under these circumstances, the assumption that the atmosphere represents the unaltered complement of the upper mantle is untenable.

4. Interaction between the mantle reservoirs has been postulated for ${ }^{3} \mathrm{He}^{25}$ and for $\mathrm{Pb}^{26}$. Transfer of these elements is most plausibly by mass transfer ${ }^{26,27}$, so that all of the rare gases must also accompany these elements. Although it was postulated ${ }^{18}$ that He diffused alone into the upper mantle, a substantial diffusive flux of $\mathrm{He}$ does not appear to be a reasonable mechanism for maintaining the global ${ }^{3} \mathrm{He}$ flux at mid-ocean ridges.

5. Evidence in support of the residual upper mantle model included the measurement of atmospheric $\mathrm{Ar}$ and $\mathrm{Xe}$ isotope compositions in ocean island basalts together with high ${ }^{3} \mathrm{He} /{ }^{4} \mathrm{He}$ ratios, which were interpreted as reflecting the lower mantle $\mathrm{Ar}$ and $\mathrm{Xe}$ isotope composition ${ }^{17,18}$. However, it now appears that the measured ratios reflect atmospheric contamination either during transit through the crust, during eruption, or at the surface ${ }^{28}$.

O'Nions and Oxburgh ${ }^{25}$ first proposed that $\mathrm{He}$ in the upper mantle is open to flows from the underlying mantle, noting that the rate at which radiogenic ${ }^{4} \mathrm{He}$ is released at mid-ocean ridges is equal to that produced in the upper mantle, and arguing that the accompanying ${ }^{3} \mathrm{He}$ is derived from 
the lower mantle. Galer and $\mathrm{O}^{\prime} \mathrm{Nions}^{26}$ argued that $\mathrm{Pb}$ is in a steady state in the upper mantle and is supported by a mass transfer from an undepleted mantle. They further noted that such a flow would also support other highly incompatible elements which are efficiently removed from the upper mantle. Kellogg and Wasserburg ${ }^{27}$ presented a detailed analysis of a model for maintaining a steady state $\mathrm{He}$ inventory in the upper mantle by mass transfer inflow of lower mantle $\mathrm{He}$ with a high ${ }^{3} \mathrm{He} /{ }^{4} \mathrm{He}$ ratio at hotspots, radiogenic production of ${ }^{4} \mathrm{He}$ within the upper mantle, and outflows to the atmosphere of $\mathrm{He}$ at ridges and hotspots by melting. The lower mantle was assumed to have evolved essentially as a closed system. Porcelli and Wasserburg ${ }^{29-31}$ extended the analysis to Xe and incorporated production of Xe by the short-lived nuclides ${ }^{129} \mathrm{I}$ and ${ }^{244} \mathrm{Pu}$ as well as ${ }^{238} \mathrm{U}$, along with subduction of Xe. These workers showed that in this model upper mantle radiogenic ${ }^{129} \mathrm{Xe}$ from extinct ${ }^{129} \mathrm{I}$ has been stored in the lower mantle, along with excess ${ }^{136} \mathrm{Xe}$ derived from extinct ${ }^{244} \mathrm{Pu} .{ }^{136} \mathrm{Xe}$ was found to be substantially augmented in the upper mantle by production from ${ }^{238} \mathrm{U}$. Porcelli and Wasserburg ${ }^{32}$ extended the model to include all of the rare gases and demonstrated the links between the isotopic shifts of ${ }^{3} \mathrm{He} /{ }^{4} \mathrm{He},{ }^{21} \mathrm{Ne} /{ }^{22} \mathrm{Ne},{ }^{40} \mathrm{Ar} /{ }^{36} \mathrm{Ar}$, and ${ }^{136} \mathrm{Xe} /{ }^{130} \mathrm{Xe}$. Ne with a high ${ }^{20} \mathrm{Ne} /{ }^{22} \mathrm{Ne}$ ratio was shown to be stored in the lower mantle.

This model contrasts with previous rare gas models by incorporating interactions between mantle reservoirs. The open system upper mantle requires long-term storage of rare gases in the lower mantle. This model has now been shown to be successful in explaining the available data for $\mathrm{He}, \mathrm{Ne}, \mathrm{Ar}$, and Xe isotope variations, and provides a unified scheme for the distribution and transfer of rare gases in the Earth. The systematics of the steady state upper mantle model will be reviewed below.

One fundamental difference between the residual upper mantle model and the steady state mantle model is that the former starts with the assumption of a closed system crust-atmosphere that is equivalent to the lower mantle, and this sets the isotopic compositions of the lower mantle. In contrast, the steady state model presented here starts with the assumption that upper mantle isotope compositions are the result of in situ radiogenic production mixed with lower mantle rare gases and subducted atmospheric rare gases. The atmosphere is considered to be a separate and isotopically distinct reservoir. The present isotopic compositions of the upper mantle then limits the isotopic compositions and concentrations of the lower mantle as well as the contributions from subduction. The lower mantle concentrations and isotopic compositions calculated for the steady state upper mantle model have specific consequences for terrestrial volatile acquisition, which will be discussed below.

\section{MODEL SYSTEMATICS}

The steady state upper mantle model is shown schematically in Figure 1 . The model assumes that the Earth initially had uniform concentrations of $\mathrm{U}, \mathrm{Th}, \mathrm{Pu}, \mathrm{I},{ }^{129} \mathrm{I}$, and $\mathrm{K}$. The Earth is divided into three reservoirs; the 'undegassed' lower mantle (P), the extensively degassed upper mantle (D), and the atmosphere-crust. Each mantle reservoir is of fixed mass and homogeneous in rare gas isotopic composition and in rare gas and parent element concentrations. The lower mantle is assumed to have evolved isotopically approximately as a closed system with in situ decay of ${ }^{129} \mathrm{I},{ }^{244} \mathrm{Pu},{ }^{238} \mathrm{U}$, ${ }^{235} \mathrm{U}^{232} \mathrm{Th}$, and ${ }^{40} \mathrm{~K}$ adding to the complement of initial rare gases. The upper mantle is open to interactions with both the atmosphere-crust and the $\mathrm{P}$ reservoir. Transfer of rare gases from the $\mathrm{P}$ reservoir into D occurs at hotspots, where a flow of material from $\mathrm{P}$ rises into $\mathrm{D}$ and a fraction degasses directly to the atmosphere, while the remainder is mixed into D. Species flows from $\mathrm{P}$ are determined by the concentrations of rare gases in the transferred masses. Rare gases also flow into the upper mantle from the atmosphere-crust by subduction. Degassing of the upper mantle occurs both at mid-ocean ridges and at hotspots, where some proportion of rising material from $\mathrm{P}$ entrains upper mantle material into plumes. It is assumed that there is no fractionation between rare gases during inter-mantle transfers or degassing. The concentrations of all the rare gases in the upper mantle are assumed to be in steady state, so that the flows of each species into $\mathrm{D}$ are equal to those out of $\mathrm{D}$. The full derivations of the governing equations are given elsewhere $29,30,32$. 
For each rare gas isotope $i$ in $\mathrm{D}$, the equation relating the flows into and out of $\mathrm{D}$ are

$$
\frac{d^{i} N_{D}}{d t}=\left[\sum_{b}^{i} P_{b} M_{D}{ }^{b} C_{D}+{ }^{i} C_{S U B} \dot{M}_{S U B}+{ }^{i} C_{P} \dot{M}_{P D}(1-r)\right]-\left[{ }^{i} C_{D} \dot{M}_{P D}{ }^{r a}+{ }^{i} C_{D} \dot{M}_{M O R}\right]=0
$$

The first three terms on the right hand side of eqn 1 are the inputs into $\mathrm{D}$; ${ }^{i} \mathrm{P}_{\mathrm{b}}$ is the production rate of $i$ in $D$ (per atom of parent) from parent nuclide $b$ that has a concentration of ${ }^{b} C_{D}$ in $D$, and $M_{D}$ is the mass of $D .{ }^{i} C_{S U B}$ is the concentration of $i$ in material subducted into $D$ at a rate of $\dot{\mathrm{M}}_{\mathrm{SUB}},{ }^{\mathrm{i}} \mathrm{C}_{\mathrm{p}}$ is the concentration of $\mathrm{i}$ in P, $\dot{\mathrm{M}}_{\mathrm{PD}}$ is the total mass flow from $\mathrm{P}$ in plumes, and $\mathrm{r}$ is the fraction of plume material that is degassed directly to the atmosphere at ridges. The last two terms are outflows from $\mathrm{D}$. The parameter a is the proportion of $\mathrm{D}$ material entrained in the plume flow, ${ }^{\mathrm{i}} \mathrm{C}_{\mathrm{D}}$ is the concentration of $i$ in $D$ and $\dot{M}_{M O R}$ is the rate at which $D$ material is stripped of rare gases at midocean ridges. In the steady-state upper mantle, $\mathrm{d}^{\mathrm{i}} \mathrm{N}_{\mathrm{D}} / \mathrm{dt}=0$.

Equation 1 can be rearranged to

$$
\frac{{ }^{i} C_{D}}{{ }^{i} C_{P}}=\frac{(1-r) \dot{M}_{P D}}{\mathrm{raM}_{\mathrm{PD}}+\dot{\mathrm{M}}_{\mathrm{MOR}}}\left(1+\delta_{\mathrm{SUB}}^{\mathrm{i}}+\delta_{\mathrm{PR}}^{\mathrm{i}}\right)
$$

where

$$
\delta_{\mathrm{SUB}}^{\mathrm{i}}=\dot{\mathrm{M}}_{\mathrm{SUB}}{ }^{\mathrm{i}} \mathrm{C}_{\mathrm{SUB}} /\left[{ }^{\mathrm{i}} \mathrm{C}_{\mathrm{P}}(1-\mathrm{r}) \dot{\mathrm{M}}_{\mathrm{PD}}\right]
$$

is the fractional increase in ${ }^{i} C_{D}$ due to the flow of $i$ from subduction relative to the flow of $i$ from $P$ and so reflects the importance of subduction for isotope $i$. In addition,

$$
\delta_{\mathrm{PR}}^{\mathrm{i}}=\sum_{\mathrm{b}}^{\mathrm{i}} \mathrm{P}_{\mathrm{b}} \mathrm{M}_{\mathrm{D}}{ }^{\mathrm{b}} \mathrm{C}_{\mathrm{D}} /\left({ }^{\mathrm{i}} \mathrm{C}_{\mathrm{P}}(1-\mathrm{r}) \dot{\mathrm{M}}_{\mathrm{PD}}\right)
$$

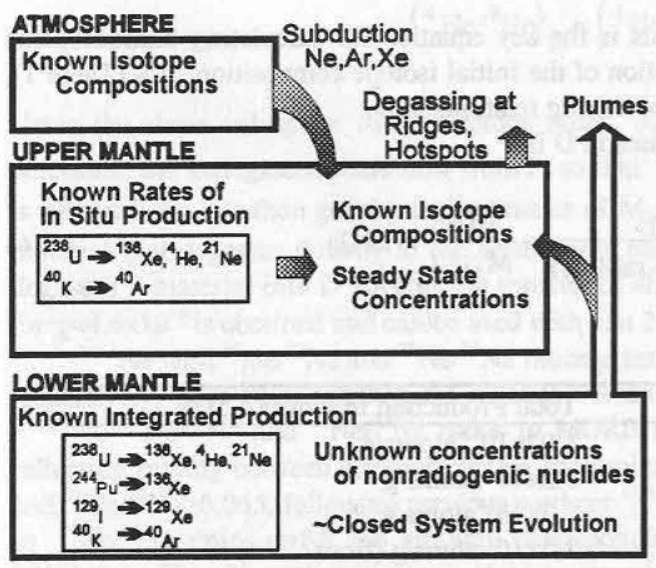

Figure 1. The steady state upper mantle model, with flows shown. See text for explanation. is the fractional increase in ${ }^{i} C_{D}$ due to production by nuclear reactions in $\mathrm{D}$ relative to the flow of $\mathrm{i}$ from P. It is this term that governs the extent to which upper mantle compositions will be more radiogenic than those of the lower mantle. For the isotopes that have no radiogenic or nuclear contributions, i.e. ${ }^{3} \mathrm{He},{ }^{20} \mathrm{Ne},{ }^{22} \mathrm{Ne},{ }^{36} \mathrm{Ar}$, and ${ }^{130} \mathrm{Xe}$, then ${ }^{\mathrm{i}} \mathrm{P}_{\mathrm{b}}=0$ and $\delta_{\mathrm{PR}}^{\mathrm{i}}=0$. The term $\chi \equiv(1-\mathrm{r}) \dot{\mathrm{M}}_{\mathrm{PD}} /\left[\mathrm{ra} \dot{\mathrm{M}}_{\mathrm{PD}}+\dot{\mathrm{M}}_{\mathrm{MOR}}\right]$ is the ratio of the rate of mass flow into $D$ to that of the mass flow from D that is outgassed, and is common to all expressions of ${ }^{i} C_{D} / C_{P}$. Equation 2 is the key for the distribution of all rare gas isotopes, and the distribution of isotopic ratios is obtained by combining eqn 2 for each isotope. Note that the volume of ridge volcanism is much greater than that of hotspots, so that $\chi \approx(1-\mathrm{r}) \dot{\mathrm{M}}_{\mathrm{PD}} / \dot{\mathrm{M}}_{\mathrm{MOR}}$.

The links between production of the isotopes of $\mathrm{He}, \mathrm{Ne}, \mathrm{Ar}$, and $\mathrm{Xe}$ are the basis 
for a unified model of rare gas isotope distributions. The relative production rates of the radiogenic rare gases are determined by the relative proportions of parent nuclides and known or estimated nuclear parameters. ${ }^{4} \mathrm{He}$ is produced by the decay of U- and Th- series nuclides as $\alpha$ particles. The $\mathrm{Th} / \mathrm{U}$ ratio is well known for global reservoirs from $\mathrm{Pb}$ and $\mathrm{Th}$ isotope studies. ${ }^{21} \mathrm{Ne}$ is produced by the reaction ${ }^{18} \mathrm{O}(\alpha, \mathrm{n}){ }^{21} \mathrm{Ne}$ and to a lesser degree by the reaction ${ }^{24} \mathrm{Mg}(\mathrm{n}, \alpha){ }^{21} \mathrm{Ne}$, and the relative production of ${ }^{21} \mathrm{Ne}$ to ${ }^{4} \mathrm{He}, \mathrm{q}={ }^{21} \mathrm{P} /{ }^{4} \mathrm{P}$, is obtained from the estimated yields of these reactions. The parameter $\mathrm{q}$ is a constant based upon nuclear parameters and the bulk mantle composition. The relative production of ${ }^{4} \mathrm{He}$ to ${ }^{40} \mathrm{Ar}$ is determined by nuclear parameters and the mantle $\mathrm{U} / \mathrm{K}$ ratio, which is well known. The production rate of ${ }^{136} \mathrm{Xe}$ relative to ${ }^{4} \mathrm{He}$ is determined by the fission yield of ${ }^{136} \mathrm{Xe}$ per decay of ${ }^{238} \mathrm{U}$ and ${ }^{244} \mathrm{Pu}$, and is fixed by well-constrained nuclear parameters. The production rate of ${ }^{136} \mathrm{Xe}$ relative to ${ }^{4} \mathrm{He}$ is determined by the fission yield of ${ }^{136} \mathrm{Xe}$ per decay of ${ }^{238} \mathrm{U}$ and ${ }^{244} \mathrm{Pu}$, and is fixed by well-constrained nuclear parameters. Since all $\delta_{P R}^{i}$ are proportional to nuclear production rates and parent element abundances, the isotopic shifts in all of the rare gases due to radiogenic production in D are correlated, although actual isotopic compositions also reflect the effects of subduction.

The total isotopic shifts in each rare gas isotope composition due to production within each mantle reservoir are proportional to the production rate of the radiogenic isotope and the rare gas residence time (i.e. the time of production). The isotopic shifts are inversely proportional to the abundance of the primordial isotopes. Therefore, isotopic shifts in each reservoir can be combined with known production rates to constrain the nonradiogenic rare gas relative abundances in $\mathrm{D}$ and $\mathrm{P}$.

The concentrations of radiogenic (and nucleogenic) rare gas nuclides produced in $4.5 \mathrm{Ga}$ in $\mathrm{P}$ are listed in Table 1 for $\mathrm{U}=5.3 \times 10^{13}$ atoms $/ \mathrm{g}(21 \mathrm{ppb})^{33}, \mathrm{Th} / \mathrm{U}=3.9$, and $(\mathrm{K} / \mathrm{U})_{\mathrm{wt}}=1.27 \times 10^{4}$ (ref. 34$)$. The abundance of $\mathrm{Pu}$ associated with terrestrial $\mathrm{U}$ at the time of meteorite formation is obtained from the ratio of $(\mathrm{Pu} / \mathrm{U})_{0}=0.0068$ obtained from meteorite data ${ }^{35}$. Early losses of radiogenic Xe isotopes may have occurred ${ }^{36,37}$. Therefore, of the total fissiogenic ${ }^{136} \mathrm{Xe}$ produced by this Pu inventory, only a fraction $\left({ }^{244} \mathrm{~F}\right)$ may have been accumulated by the Earth. The calculations presented here use ${ }^{244} \mathrm{~F}=0.5$. Note that production of ${ }^{136} \mathrm{Xe}$ in $\mathrm{P}$ is dominated by decay of ${ }^{244} \mathrm{Pu}$ (Table 1). The present production rates in $\mathrm{D}$ are also listed for $\mathrm{U}=8.0 \times 10^{12}$ atoms $/ \mathrm{g}$, $\mathrm{Th} / \mathrm{U}=2.6$, and $(\mathrm{K} / \mathrm{U})_{\mathrm{wt} .}=1.27 \times 10^{4}$.

In the lower mantle, the concentrations of nonradiogenic nuclides ${ }^{n} C_{P}$ and radiogenic nuclides ${ }^{i *} C_{P}$ are related to the isotopic shift $\Delta_{P}^{i / n}$ from the initial isotope ratio to the present ratio by

$$
\Delta \Delta_{\mathrm{P}}^{\mathrm{i} / \mathrm{n}} \equiv\left({ }^{\mathrm{i}} \mathrm{C}_{\mathrm{P}} /{ }^{\mathrm{n}} \mathrm{C}_{\mathrm{P}}\right)-\left({ }^{\text {io }} \mathrm{C}_{\mathrm{P}} /{ }^{\mathrm{n}} \mathrm{C}_{\mathrm{P}}\right)={ }^{\mathrm{i}} \mathrm{C}_{\mathrm{P}} /{ }^{\mathrm{n}} \mathrm{C}_{\mathrm{P}}
$$

where ${ }^{\text {io }} \mathrm{C}_{\mathrm{P}}$ is the initial concentration of $i$. This is the key equation for calculating nonradiogenic isotope concentrations in $\mathrm{P}\left({ }^{\mathrm{n}} \mathrm{C}_{\mathrm{P}}\right.$ ) from specification of the initial isotope composition, ${ }^{{ }^{*}} \mathrm{C}_{\mathrm{P}}$ (Table 1 ), and the present isotope ratio determined from the mixing relations in $\mathrm{D}$.

The residence time for all of the rare gases in $\mathrm{D}$ is ${ }^{27}$

$$
\tau_{\mathrm{i}}=\frac{{ }^{\mathrm{i}} \mathrm{C}_{\mathrm{D}} \mathrm{M}_{\mathrm{D}}}{{ }^{\mathrm{i}} \mathrm{C}_{\mathrm{D}}\left(\dot{\mathrm{M}}_{\mathrm{MOR}}+\mathrm{raM} \dot{\mathrm{M}}_{\mathrm{PD}}\right)} \approx \frac{\mathrm{M}_{\mathrm{D}}}{\dot{\mathrm{M}}_{\mathrm{MOR}}}=1.4 \mathrm{Ga}
$$

\section{TABLE 1}

\begin{tabular}{l|ll}
\hline Nuclide & Present Production Rate in D & Total Production in P over $4.5 \mathrm{Ga}$ \\
\hline${ }^{4 *} \mathrm{He}$ & $1.7 \times 10^{4}$ atoms $/ \mathrm{g}-\mathrm{yr}$ & $1.02 \times 10^{15}$ atoms $/ \mathrm{g}$ \\
${ }^{211^{*}} \mathrm{Ne}$ & $1.5 \times 10^{-3}$ atoms $/ \mathrm{g}-\mathrm{yr}$ & $9.2 \times 10^{7}$ atoms $/ \mathrm{g}$ \\
${ }^{40^{*}} \mathrm{Ar}$ & $4.5 \times 10^{3}$ atoms $/ \mathrm{g}-\mathrm{yr}$ & $5.7 \times 10^{14}$ atoms $/ \mathrm{g}$ \\
${ }^{136^{*} \mathrm{Xe}}$ & $4.30 \times 10^{-5}$ atoms $/ \mathrm{g}-\mathrm{yr}$ & $2.5 \times 10^{7}$ atoms $/ \mathrm{g}\left(\right.$ from $\left.^{244} \mathrm{Pu}\right)$ \\
& & $1.9 \times 10^{6}$ atoms $/ \mathrm{g}\left(\mathrm{from}^{238} \mathrm{U}\right)$ \\
\hline
\end{tabular}


where $\mathrm{M}_{\mathrm{D}}=1 \times 10^{27} \mathrm{~g}$ and $\dot{\mathrm{M}}_{\mathrm{MOR}}=7 \times 10^{17} \mathrm{~g} / \mathrm{yr}$.

\section{RARE GAS ISOTOPE COMPOSITIONS AND ABUNDANCES}

The mechanics of the model are summarized in Figure 1. The balance of flows into and out of $\mathrm{D}$ is represented in eqns. 1-4. The key isotopic relationships (obtained by combining the equations for each isotope) are the mixing of inputs into D to produce the present isotopic compositions in D, which are constrained by the available MORB data. The rates of in situ production are known (Table 1). The flow of rare gases from the atmosphere in subducted materials of known isotope composition but unknown concentrations, must be balanced by the flow of rare gases from the lower mantle, with generally unknown isotope compositions but known concentrations of radiogenic nuclides. The isotopic compositions in the lower mantle and the concentrations of nonradiogenic nuclides there are coupled by the closed system evolution equation (eqn. 5). As shown below, the simpliest case is for $\mathrm{He}$, where it is argued that there is no subduction flux and the isotopic composition of both mantle reservoirs is well constrained. A flux of ${ }^{4} \mathrm{He}$ from $\mathrm{P}$ to D can be calculated, and this corresponds to a flux of material that excapes degassing at hotspots and mixes into D. By coupling the He fluxes with those of $\mathrm{Ne}$, the isotopic distribution of the $\mathrm{Ne}$ isotopes are derived. For $\mathrm{Ar}$ and $\mathrm{Xe}$, we argue subduction may be significant and there are no constraints available for the isotopic compositions of P. However, it will be shown that lower limits can be placed upon the lower mantle ${ }^{40} \mathrm{Ar} /{ }^{36} \mathrm{Ar}$, ${ }^{129} \mathrm{Xe} /{ }^{130} \mathrm{Xe}$, and ${ }^{136} \mathrm{Xe} /{ }^{130} \mathrm{Xe}$ ratios, and so upon the concentrations of $\mathrm{Ar}$ and $\mathrm{Xe}$.

The model results for He were explored in detail by Kellogg and Wasserburg ${ }^{27}$. The isotopic composition of $\mathrm{He}$ in both mantle reservoirs can be estimated from available data. The $\left({ }^{3} \mathrm{He} /{ }^{4} \mathrm{He}\right)_{\mathrm{D}}$ ratio is taken from data for mid-ocean ridge basalts (MORB), which have a relatively uniform and well-constrained value of ${ }^{3} \mathrm{He} /{ }^{4} \mathrm{He}=1.1 \times 10^{-5}$ (ref. 5). The value for $\mathrm{P}$ is taken from ocean island volcanics which have ${ }^{3} \mathrm{He} /{ }^{4} \mathrm{He}$ ratios that are greater than those in MORB and are generally considered to reflect contributions of $\mathrm{He}$ from a less degassed lower mantle ${ }^{17,38}$. The highest measured ratio of ${ }^{3} \mathrm{He} /{ }^{4} \mathrm{He}=4.5 \times 10^{-5}$ from the Loihi hotspot ${ }^{39}$ is taken as the value for P. An initial composition of ${ }^{3} \mathrm{He} /{ }^{4} \mathrm{He}=1.43 \times 10^{-4}$ is taken from the 'planetary' component of meteorites ${ }^{40}$. The concentrations of $\mathrm{He}$ isotopes in $\mathrm{P}$ can be obtained immediately from eqn. 5 (Table 2) and are fixed.

From the $\mathrm{He}$ isotopic compositions of the mantle reservoirs and the rates of ${ }^{4} \mathrm{He}$ production, the undegassed mass flux from P to D can be calculated. From eqn. 2 for ${ }^{3} \mathrm{He}$ and ${ }^{4} \mathrm{He}$ (with $\left.\delta_{\text {SUB }}^{3}=\delta_{\text {SUB }}^{4}=0\right)$,

$$
\left({ }^{4} \mathrm{He} /{ }^{3} \mathrm{He}\right)_{\mathrm{D}}=\left({ }^{4} \mathrm{He} /{ }^{3} \mathrm{He}\right)_{\mathrm{P}}\left(1+\delta_{\mathrm{PR}}^{4}\right)
$$

Using the above values for the He isotope ratios, $\delta_{\mathrm{PR}}^{4}=3.1$. This value can be used with eqn. 4 to determine the undegassed mass flow from $\mathrm{P}$, so that $(1-r) \dot{M}_{P D}=3.7 \times 10^{15} \mathrm{~g} / \mathrm{yr}$. Note that since this is substantially less than geophysical estimates of $\dot{M}_{\mathrm{PD}}=(2-20) \times 10^{16} \mathrm{~g} / \mathrm{yr}$, the fraction of rising plume material that degasses directly to the atmosphere must be large ( $r>0.84)^{27}$. The mass flow of nondegassed $\mathrm{P}$ material into $\mathrm{D}$ governs the transfer of all rare gas nuclides from $\mathrm{P}$ into $\mathrm{D}$. Also, a value for $\chi \approx 4.6 \times 10^{-3}$ is obtained and can be used with eqn 2 to obtain upper mantle rare gas concentrations.

$\mathrm{Ne}$ with ${ }^{20} \mathrm{Ne} /{ }^{22} \mathrm{Ne}$ and ${ }^{21} \mathrm{Ne} /{ }^{22} \mathrm{Ne}$ ratios greater than the atmospheric values of 9.8 and 0.029 , respectively, have been reported for Kilauea volcanic gases ${ }^{6}$, ultramafic xenoliths ${ }^{41}$, and MORB $6,7,8,41,42 .{ }^{20} \mathrm{Ne} /{ }^{22} \mathrm{Ne}$ and ${ }^{21} \mathrm{Ne} /{ }^{22} \mathrm{Ne}$ ratios in MORB are correlated (Figure 2). We interpret this as reflecting mixing between atmospheric Ne contamination and mantle Ne which has ${ }^{20} \mathrm{Ne} /{ }^{22} \mathrm{Ne} \geq 12.5$ and ${ }^{21} \mathrm{Ne} / 22 \mathrm{Ne} \geq 0.065$, following previous workers ${ }^{43,44}$. Ne measured in hotspots span a similar range in ${ }^{20} \mathrm{Ne} /{ }^{22} \mathrm{Ne}$ ratios as MORB but with corresponding ${ }^{21} \mathrm{Ne} /{ }^{22} \mathrm{Ne}$ ratios that are substantially lower ${ }^{8.45-48}$ (see Fig. 2) and this range is also considered to be due to the effects of atmospheric contamination.

Solar system compositions with ${ }^{20} \mathrm{Ne} /{ }^{22} \mathrm{Ne}$ ratios greater than that of the atmosphere are 
shown in Fig. 2. 'Solar' $\mathrm{Ne}$ as measured in trapped solar wind ${ }^{50,52}$, lunar soils ${ }^{51}$, and gas-rich meteorites ${ }^{49}$ have ratios of ${ }^{21} \mathrm{Ne} /{ }^{22} \mathrm{Ne}=0.032$, and this is taken here as the value for $\mathrm{Ne}$ initially trapped in the Earth. The measured ${ }^{20} \mathrm{Ne} /{ }^{22} \mathrm{Ne}$ ratios in these compositions are substantially different. The ratio for gas-rich meteorites of ${ }^{20} \mathrm{Ne} /{ }^{22} \mathrm{Ne}=12.5$ is similar to the value for $\mathrm{D}^{\prime}$ taken from MORB analyses (Fig. 2). If this value pertains to Ne trapped within the Earth and so to $\mathrm{Ne}$ in $\mathrm{P}$, then subduction of atmospheric Ne has not significantly changed the ${ }^{20} \mathrm{Ne} /{ }^{22} \mathrm{Ne}$ ratio of $\mathrm{Ne}$ in $\mathrm{D}$ from that in $\mathrm{P}$. Therefore, $\delta_{\mathrm{SUB}}^{22} \approx 0$. If the ratio for trapped solar wind of ${ }^{20} \mathrm{Ne} /{ }^{22} \mathrm{Ne}=13.6$ pertains to $\mathrm{Ne}$ trapped in $\mathrm{P}$, then the minimum value for $\mathrm{D}$ is lower than that of $\mathrm{P}$, and $\delta_{\mathrm{SUB}}^{22} \leq 0.4$. In this case, Ne in $\mathrm{D}$ is still dominantly from P. For simplicity, we will use $\delta_{\text {SUB }}^{22}=0$ below.

The systematics of $\mathrm{Ne}$ are analogous to $\mathrm{He}$, and

$$
\left({ }^{21} \mathrm{Ne} /{ }^{22} \mathrm{Ne}\right)_{\mathrm{D}}=\left({ }^{21} \mathrm{Ne} /{ }^{22} \mathrm{Ne}\right)_{\mathrm{P}}\left(1+\delta_{\mathrm{PR}}^{21}\right)
$$

We define $\Delta_{\mathrm{D}}^{21 / 22}$ as the isotopic shift in the ${ }^{21} \mathrm{Ne} /{ }^{22} \mathrm{Ne}$ ratio due to radiogenic addition of ${ }^{21} \mathrm{Ne}$ in $\mathrm{D}$ to $\mathrm{Ne}$ derived from $\mathrm{P}$, so that $\Delta_{\mathrm{D}}^{21 / 22} \equiv\left({ }^{21} \mathrm{Ne} /{ }^{22} \mathrm{Ne}\right)_{\mathrm{D}}-\left({ }^{21} \mathrm{Ne} /{ }^{22} \mathrm{Ne}\right)_{\mathrm{P}}$. Similarly, we define $\Delta_{\mathrm{D}}^{4 / 3} \equiv\left({ }^{4} \mathrm{He} /{ }^{3} \mathrm{He}\right)_{\mathrm{D}}-\left({ }^{4} \mathrm{He} /{ }^{3} \mathrm{He}\right)_{\mathrm{P}}$. Combining eqns 7 and 8 ,

$$
\left(\frac{\Delta_{\mathrm{D}}^{21 / 22}}{\Delta_{\mathrm{P}}^{21 / 22}}\right)=\left(\frac{\Delta_{\mathrm{D}}^{4 / 3}}{\Delta_{\mathrm{P}}^{4 / 3}}\right)
$$

It follows that the ratio of the isotopic shift in $\mathrm{D}$ (the increase in ${ }^{21} \mathrm{Ne} /{ }^{22} \mathrm{Ne}$ in $\mathrm{D}$ relative to that in $\mathrm{P}$ ), to the isotopic shift in $\mathrm{P}$ (the increase in ${ }^{21} \mathrm{Ne} /{ }^{22} \mathrm{Ne}$ in $\mathrm{P}$ relative to the initial value) is the same as the ratio of the corresponding shifts in ${ }^{4} \mathrm{He} /{ }^{3} \mathrm{He}$. Using the values for the isotopic compositions of $\mathrm{He}$

MORB DATA

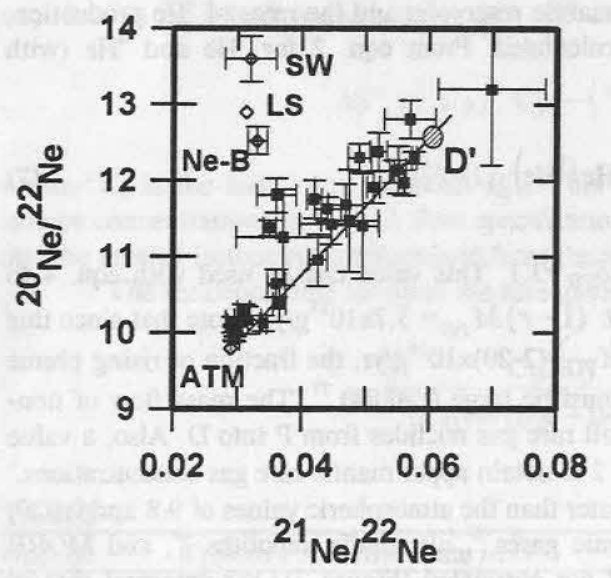

OCEAN ISLAND DATA

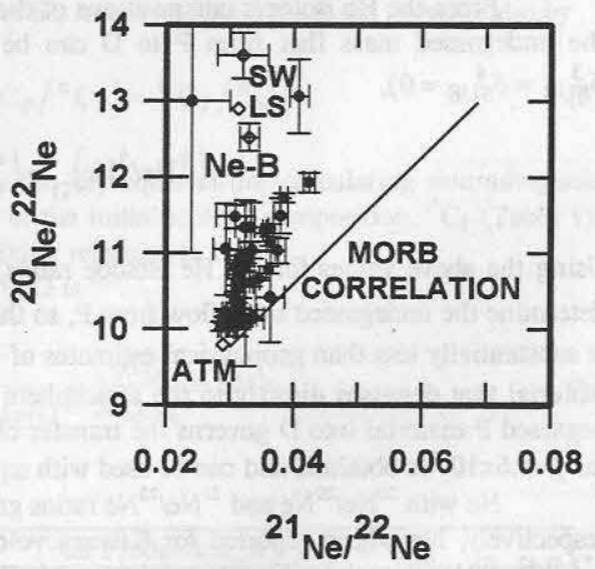

Figure 2. Ne isotope data for mid-ocean ridge basalts ${ }^{6,8,41,42}$ and ocean islands (hotspots) ${ }^{8,45-48}$. Note the separate correlations of MORB and ocean island data extending from atmospheric values, reflecting variable atmospheric contamination to mantle Ne. The 'solar' values are from gas-rich meteorites $(\mathrm{Ne}-\mathrm{B})^{49}$, lunar soils $(\mathrm{LS})^{51}$, and solar wind $(\mathrm{SW})^{50,52} . \mathrm{D}$ ' is the minimum value for $\mathrm{D}$. 
discussed above, the right hand side of eqn 9 is equal to 4.4. Therefore, the shift in ${ }^{21} \mathrm{Ne} /{ }^{22} \mathrm{Ne}$ generated in the upper mantle by the ${ }^{18} \mathrm{O}(\alpha, \mathrm{n})^{21} \mathrm{Ne}$ and ${ }^{24} \mathrm{Mg}(\mathrm{n}, \alpha)^{21} \mathrm{Ne}$ reactions is 4.4 times larger than those generated by the same processes in the lower mantle. This is due to the extensive outgassing of $\mathrm{D}$ and the substantial concentration of $\mathrm{U}$ in $\mathrm{D}$ relative to the rare gases. If $\left({ }^{21} \mathrm{Ne} /{ }^{22} \mathrm{Ne}\right)_{\mathrm{D}}$ $=0.065$ and $\left({ }^{21} \mathrm{Ne} /{ }^{22} \mathrm{Ne}\right)_{\mathrm{O}}=0.032$, then $\left({ }^{21} \mathrm{Ne} /{ }^{22} \mathrm{Ne}\right)_{\mathrm{P}}=0.038$ and $\Delta_{P}^{21 / 22}=0.006$. This value for $\left({ }^{21} \mathrm{Ne} /{ }^{22} \mathrm{Ne}\right)_{\mathrm{P}}$ is compatible with the ocean island basalt data (Figure 2). The concentrations of ${ }^{22} \mathrm{Ne}$ and ${ }^{20} \mathrm{Ne}$ in $\mathrm{P}$ and $\mathrm{D}$ can be calculated from eqns 2 and 5 (Table 2) and are fixed by the value for $\Delta_{P}^{21 / 22}$.

Measured ${ }^{40} \mathrm{Ar} /{ }^{36} \mathrm{Ar}$ ratios in MORB vary widely due to mixing of mantle Ar with variable proportions of atmospheric Ar contamination ${ }^{17,53-55}$. The highest value of $2.8 \times 10^{4}$ (ref. 55 ) is the minimum value for the MORB source and for computational purposes is taken here as the value for D. Hotspot volcanics with high ${ }^{3} \mathrm{He} /{ }^{4} \mathrm{He}$ ratios typically have measured ${ }^{40} \mathrm{Ar} /{ }^{36} \mathrm{Ar}$ ratios similar to atmospheric $\mathrm{Ar}^{\mathrm{eg}{ }^{17,47}}$. It has been argued ${ }^{28}$ that $\mathrm{Ar}$ in these samples is highly contaminated with atmospheric $\mathrm{Ar}$ and does not reflect mantle compositions. Therefore, the ${ }^{40} \mathrm{Ar} /{ }^{36} \mathrm{Ar}$ value of $\mathrm{P}$ is considered unknown. The initial ${ }^{40} \mathrm{Ar} /{ }^{36} \mathrm{Ar}$ ratio in the solar system is $\sim 10^{-3}$ (ref. 56); essentially all terrestrial ${ }^{40} \mathrm{Ar}$ is radiogenic.

Argon systematics are coupled to those of $\mathrm{He}$ by nuclear parameters. It has been argued that $\mathrm{K}$ and $\mathrm{U}$ have not been fractionated in global differentiation processes and so in the model $\mathrm{K} / \mathrm{U}$ is the same in D and $\mathrm{P}$. The difference between the ${ }^{4 *} \mathrm{He}{ }^{40^{*}}$ Ar production ratio in D (integrated over the last $1.4 \mathrm{Ga}$ ) and ${ }^{4 *} \mathrm{He} /{ }^{40^{*}} \mathrm{Ar}$ in $\mathrm{P}$ (integrated over $4.5 \mathrm{Ga}$ ) is due to the different half-lives of ${ }^{238} \mathrm{U}$ and ${ }^{40} \mathrm{~K}$. Using eqn 4 for $\delta_{\mathrm{PR}}^{40}$ and for $\delta_{\mathrm{PR}}^{4}$ (with a value calculated using the chosen He isotope compositions) so that the mass terms and parent element concentrations cancel, a value of $\delta_{\mathrm{PR}}^{40}=1.9$ is obtained. This indicates that the radiogenic production of ${ }^{40} \mathrm{Ar}$ in the upper mantle is 1.9 times greater than the flow of radiogenic ${ }^{40} \mathrm{Ar}$ from $\mathrm{P}$ into $\mathrm{D}$.

The isotopic compositions of $\mathrm{Ar}$ in $\mathrm{D}$ and $\mathrm{P}$ are related by:

$$
\left({ }^{40} \mathrm{Ar} /{ }^{36} \mathrm{Ar}\right)_{\mathrm{P}}=\left({ }^{40} \mathrm{Ar} /{ }^{36} \mathrm{Ar}\right)_{\mathrm{D}} \frac{1+\delta_{\mathrm{SUB}}^{36}}{1+\delta_{\mathrm{PR}}^{40}}=9700\left(1+\delta_{\mathrm{SUB}}^{36}\right)
$$

$\left({ }^{40} \mathrm{Ar} /{ }^{36} \mathrm{Ar}\right)_{\mathrm{P}}$ is much greater than $\left({ }^{40} \mathrm{Ar} /{ }^{36} \mathrm{Ar}\right)_{\mathrm{ATM}}$, with a minimum value of 9700 for $\delta_{\mathrm{SUB}}^{36}=0$.

\section{TABLE 2}

\begin{tabular}{lllll} 
& $\mathrm{D}$ & $\mathrm{P}$ & Initial & Atmosphere \\
\hline${ }^{3} \mathrm{C}_{i}$ (atoms/g) & $3.1 \times 10^{8}$ & $6.8 \times 10^{10}$ & $6.7 \times 10^{10}$ & - \\
${ }^{20} \mathrm{C}_{\mathrm{i}}$ (atoms/g) & $8.6 \times 10^{8}$ & $1.9 \times 10^{11}$ & $1.9 \times 10^{11}$ & $1.75 \times 10^{12}$ \\
${ }^{36} \mathrm{C}_{\mathrm{i}}$ (atoms/g) & $2.7 \times 10^{8}$ & $\leq 5.9 \times 10^{10}$ & $\leq 5.9 \times 10^{10}$ & $3.35 \times 10^{12}$ \\
${ }^{130} \mathrm{C}_{\mathrm{i}}$ (atoms/g) & $-6 \times 10^{5}$ & $\leq 1.1 \times 10^{8}$ & $\leq 9.8 \times 10^{7}$ & $3.77 \times 10^{8}$ \\
${ }^{3} \mathrm{He} /{ }^{4} \mathrm{He}$ & $1.1 \times 10^{-5}$ & $4.5 \times 10^{-5}$ & $1.43 \times 10^{-4}$ & $1.4 \times 10^{-6}$ \\
${ }^{20} \mathrm{Ne} /{ }^{22} \mathrm{Ne}$ & 12.5 & 12.5 & 12.5 & 9.8 \\
${ }^{21} \mathrm{Ne} /{ }^{22} \mathrm{Ne}$ & 0.065 & 0.038 & 0.032 & 0.029 \\
${ }^{40} \mathrm{Ar} /{ }^{36} \mathrm{Ar}$ & $2.8 \times 10^{4}$ & $\geq 9700$ & $10^{-3}$ & 296 \\
${ }^{136} \mathrm{Xe} /{ }^{130} \mathrm{Xe}$ & 2.45 & $\geq 2.34$ & 2.11 & 2.176 \\
${ }^{129} \mathrm{Xe} /{ }^{130} \mathrm{Xe}$ & 7.35 & $\geq 7.35$ & 6.05 & 6.496 \\
\hline
\end{tabular}

Concentrations in D and P are calculated. Isotope ratios in D are inferred from MORB data; those in $\mathrm{P}$ are calculated, except for $\mathrm{He}$, which is inferred from OIB data. Initial isotope ratios are from meteorite data, and initial concentrations are equal to those of $\mathrm{P}$. Concentrations for the atmosphere are atmospheric abundances divided by mass of the upper mantle $\left(1 \times 10^{27} \mathrm{~g}\right)$. See text for references. 
$\left({ }^{40} \mathrm{Ar} /{ }^{36} \mathrm{Ar}\right)_{\mathrm{P}}$ is larger if a substantial proportion of $\mathrm{Ar}$ in $\mathrm{D}$ is derived from subduction. The concentration of ${ }^{36} \mathrm{Ar}$ in $\mathrm{P}$ can be readily obtained from the $\left({ }^{40} \mathrm{Ar} /{ }^{36} \mathrm{Ar}\right)_{\mathrm{P}}$ ratio (eqn 5). Note that since the amount of radiogenic ${ }^{40} \mathrm{Ar}$ in $\mathrm{P}$ is fixed, greater.values of $\left({ }^{40} \mathrm{Ar} /{ }^{36} \mathrm{Ar}\right)_{\mathrm{P}}$ correspond to smaller concentrations of ${ }^{36} \mathrm{Ar}$ in $\mathrm{P}$.

Using the $\left({ }^{40} \mathrm{Ar} /{ }^{36} \mathrm{Ar}\right)_{\mathrm{P}}$ ratio calculated by eqn. 10 as a function of $\delta_{\mathrm{SUB}}^{36}$, the concentration of ${ }^{36} \mathrm{Ar}$ in the lower mantle can be obtained from eqn 3. For the case of no subduction of $\mathrm{Ar}$, ${ }^{36} \mathrm{C}_{\mathrm{P}}=5.9 \times 10^{10}$ atoms/g. Greater proportions of subducted $\mathrm{Ar}$ in $\mathrm{D}\left(\delta_{\mathrm{SUB}}^{36}>0\right)$ gives greater values of $\left({ }^{40} \mathrm{Ar} /{ }^{36} \mathrm{Ar}\right)_{\mathrm{P}}$, so that the value of ${ }^{36} \mathrm{C}_{\mathrm{P}}$ decreases. The concentration of ${ }^{36} \mathrm{Ar}$ in $\mathrm{D}$ is obtained by combining eqn. 2 for ${ }^{36} \mathrm{Ar}$ and eqn. 10 (see ref. 30 for derivation);

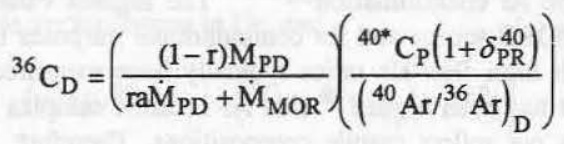

Note that the calculated value of ${ }^{36} \mathrm{C}_{\mathrm{D}}$ is independent of $\delta_{\text {SUB }}^{36}$. Using the values for each parameter as discussed above, ${ }^{36} \mathrm{C}_{\mathrm{D}}=2.7 \times 10^{8}$ atoms $/ \mathrm{g}$.

No isotopic variations have been observed or are expected between $\mathrm{Kr}$ in the various reservoirs, and so $\mathrm{Kr}$ will not be discussed further. Measured MORB ${ }^{129} \mathrm{Xe} /{ }^{130} \mathrm{Xe}$ and ${ }^{136} \mathrm{Xe} /{ }^{130} \mathrm{Xe}$ ratios ${ }^{11,17,42,45,55}$ (Figure 3) are correlated ${ }^{11}$ and extend from the composition of the atmosphere. This is interpreted here as reflecting mixing of atmospheric contaminant Xe with a mantle component. The highest ratios of ${ }^{129} \mathrm{Xe} /{ }^{130} \mathrm{Xe}=7.35$ and ${ }^{136} \mathrm{Xe} /{ }^{130} \mathrm{Xe}=2.45^{\text {ref } 55}$ are lower bounds (D') for the mantle component, and for computational purposes are taken here as the values for $\mathrm{D}$. Xe from hotspot volcanics have atmospheric isotope compositions ${ }^{\text {eg } 17}$; this has been interpreted as reflecting atmospheric contaminant $\mathrm{Xe}{ }^{28}$. Therefore, the isotopic composition of $\mathrm{Xe}$ in $\mathrm{P}$ is considered unknown. Identifying an initial Xe isotope composition for the Earth is difficult due to the complexity of solar system components ${ }^{37}$, although the specific value chosen is not critical to the model results ${ }^{29}$.
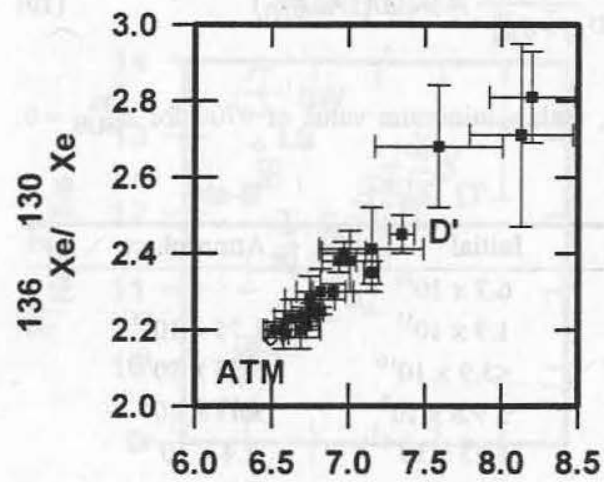

\section{$129 \mathrm{Xel}^{130} \mathrm{Xe}$}

Figure 3. Xe isotope ratios for MORB ${ }^{11,17,42,45,55}$. The observed correlation ${ }^{11}$ is interpreted as reflecting variable proportions of atmospheric contamination to a MORB Xe composition. The highest precise MORB analysis, D', is the minimum composition of $\mathrm{D}$.

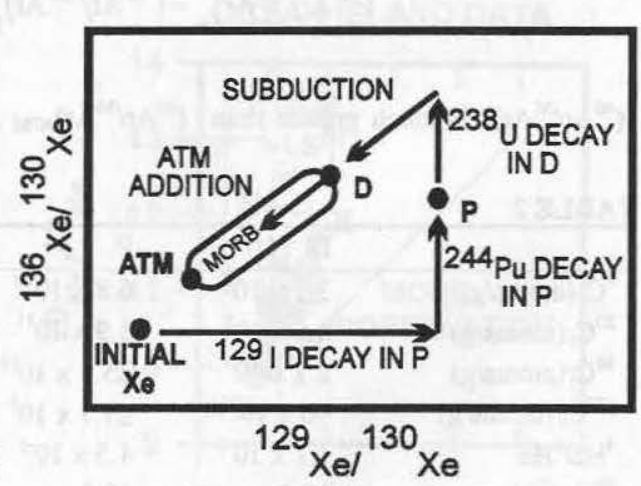

Figure 4. The general pattern of Xe evolution. ${ }^{129} \mathrm{Xe}$ and ${ }^{136} \mathrm{Xe}$ are increased in $\mathrm{P}$ by decay of ${ }^{129} \mathrm{I}$ and ${ }^{244} \mathrm{Pu}$, producing the $\mathrm{P}$ composition. Xe transferred into $\mathrm{D}$ is mixed with ${ }^{136} \mathrm{Xe}$ from decay of $U$ in $D$ and with subducted Xe, resulting in the $\mathrm{D}$ composition. Varying degrees of contamination produces the MORB array. 
In this study, we will use the most recent estimates for nonradiogenic, atmospheric Xe of $\left({ }^{136} \mathrm{Xe} /{ }^{130} \mathrm{Xe}\right)_{0}=2.11$ and $\left({ }^{129} \mathrm{Xe} /{ }^{130} \mathrm{Xe}\right)_{0}=6.05{ }^{37,57}$. Measurements of $\mathrm{Xe}$ in $\mathrm{CO}_{2}$ well gas samples suggest that a different, 'solar' nonradiogenic Xe composition may be present within the Earth ${ }^{58}$. The use of other nonradiogenic compositions for the lower mantle will not qualitatively change the conclusions drawn here (see ref. 29 for discussion).

A value for $\delta_{\mathrm{PR}}^{136^{*}}=0.46$ is obtained using eqn 4 for both $\delta_{\mathrm{PR}}^{136^{*}}$ and $\delta_{\mathrm{PR}}^{4}$, so that the mass terms and parent element concentrations cancel. This is the input of the radiogenic ${ }^{136} \mathrm{Xe}$ into the upper mantle produced by ${ }^{238} \mathrm{U}$ decay in $\mathrm{D}$ relative to the flow of radiogenic ${ }^{136} \mathrm{Xe}$ from $\mathrm{P}$, which was produced by ${ }^{244} \mathrm{Pu}$ decay. The ${ }^{136} \mathrm{Xe}$ excess in D therefore is composed of plutogenic ${ }^{136} \mathrm{Xe}$ from $\mathrm{P}$ substantially augmented by uranogenic ${ }^{136} \mathrm{Xe}$ produced in $\mathrm{D}$.

The isotopic compositions of $\mathrm{D}$ and $\mathrm{P}$ are related by:

$$
\begin{aligned}
& \left({ }^{129} \mathrm{Xe} /{ }^{130} \mathrm{Xe}\right)_{\mathrm{P}}=\left({ }^{129} \mathrm{Xe} /{ }^{130} \mathrm{Xe}\right)_{\mathrm{D}}\left(1+\delta_{\mathrm{SUB}}^{130}\right)-\left({ }^{129} \mathrm{Xe} /{ }^{130} \mathrm{Xe}\right)_{\mathrm{ATM}} \delta_{\mathrm{SUB}}^{130} \\
& \left({ }^{136} \mathrm{Xe} /{ }^{130} \mathrm{Xe}\right)_{\mathrm{P}}=\frac{\left({ }^{136} \mathrm{Xe} /{ }^{130} \mathrm{Xe}\right)_{\mathrm{D}}\left(1+\delta_{\mathrm{SUB}}^{130}\right)-\left({ }^{136} \mathrm{Xe} /{ }^{130} \mathrm{Xe}\right)_{\mathrm{ATM}} \delta_{\mathrm{SUB}}^{130}}{1+\delta_{\mathrm{PR}}^{136}}
\end{aligned}
$$

Equation 12 is a simple mixing relationship, where the fraction of ${ }^{130} \mathrm{Xe}$ in D from subduction is $\mathrm{X}_{130} \equiv \delta_{\mathrm{SUB}}^{130} /\left(1+\delta_{\mathrm{SUB}}^{130}\right)$. Note that subduction of Xe lowers the ${ }^{129} \mathrm{Xe} /{ }^{130} \mathrm{Xe}$ ratio of $\mathrm{Xe}$ provided from $\mathrm{P}$, so that $\left({ }^{129} \mathrm{Xe} /{ }^{130} \mathrm{Xe}\right)_{\mathrm{P}} \geq\left({ }^{129} \mathrm{Xe} /{ }^{130} \mathrm{Xe}\right)_{\mathrm{D}}$ and the ${ }^{129} \mathrm{Xe}$ excesses in the mantle must be stored in $\mathrm{P}$. Similarly, equation 13 can be viewed as a mixing relation between $\mathrm{Xe}$ from $\mathrm{P}$ and subduction, with the addition of radiogenic ${ }^{136} \mathrm{Xe}$ produced in D. For greater values of $\delta_{S U B}^{130}$, both $\left({ }^{129} \mathrm{Xe} /{ }^{130} \mathrm{Xe}\right)_{\mathrm{P}}$ and $\left({ }^{136} \mathrm{Xe} /{ }^{130} \mathrm{Xe}\right)_{\mathrm{P}}$ are greater and ${ }^{130} \mathrm{C}_{\mathrm{P}}$ is smaller (eqn 3). The minimum values for the isotopic composition of $\mathrm{P}$, and the maximum concentration of ${ }^{130} \mathrm{Xe}$ in $\mathrm{P}$, are listed in Table 2 . It has been shown earlier ${ }^{29}$ that the very limited data available for subducting materials do not rule out derivation of a substantial proportion of upper mantle ${ }^{130} \mathrm{Xe}$ by subduction.

The concentration of radiogenic ${ }^{129} \mathrm{Xe}$ in $\mathrm{P}$ can be calculated from eqn 5 using values for $\left({ }^{129} \mathrm{Xe} /{ }^{130} \mathrm{Xe}\right)_{\mathrm{P}}$ calculated from eqn. 12 . It can be shown that for all values of $\delta_{\mathrm{SUB}}^{130},{ }^{129^{*}} \mathrm{C}_{\mathrm{P}} / /^{136^{*}} \mathrm{C}_{\mathrm{P}} \approx 3.8$ (ref. 29). This is $10^{4}$ times less than the solar system value of $\sim 2 \times 10^{4}$ (see ref. 29), indicating that there has been substantial depletion in ${ }^{129} \mathrm{I}$ in the Earth prior to retention of radiogenic Xe.

The general pattern of mantle Xe isotopic evolution is shown in Figure 4. Starting with the initial Xe isotope composition, the ${ }^{129} \mathrm{Xe} /{ }^{130} \mathrm{Xe}$ and ${ }^{136} \mathrm{Xe} /{ }^{130} \mathrm{Xe}$ ratios in $\mathrm{P}$ are increased by the decay of ${ }^{129} \mathrm{I}$ and ${ }^{244} \mathrm{Pu}$, respectively, to produce the present $\mathrm{P}$ composition. Small amounts of Xe are transferred into $\mathrm{D}$, where due to a higher ${ }^{238} \mathrm{U} /{ }^{136} \mathrm{Xe}$ ratio the ${ }^{136} \mathrm{Xe} /{ }^{130} \mathrm{Xe}$ ratio is increased by spontaneous fission production of ${ }^{136} \mathrm{Xe}$ during the residence time of $\mathrm{Xe}$ in $\mathrm{D}$. This $\mathrm{Xe}$ is also mixed with subducted atmospheric Xe, resulting in composition D. The observed range in MORB samples is attributed to variable proportions of atmospheric contamination added in the crust or at the surface.

\section{MANTLE RARE GAS RELATIVE ABUNDANCES}

From the concentrations in Table $2,{ }^{3} \mathrm{C}_{\mathrm{P}} /{ }^{20} \mathrm{C}_{\mathrm{P}}=0.36$. This is comparable with a solar wind value of $0.26^{\text {ref } 52}$ and an order of magnitude greater than the value of 0.031 for the 'planetary' component of meteorites ${ }^{59}$. This similarity of the light rare gas relative abundances in $\mathrm{P}$ with solartype rare gases is compatible with $\mathrm{Ne}$ in the lower mantle having a 'solar' isotopic composition. Note that Honda et al. ${ }^{43}$ and O'Nions and Tolstikhin ${ }^{60}$ have also argued that the lower mantle has a solar ${ }^{3} \mathrm{He} /{ }^{20} \mathrm{Ne}$ ratio.

The lower mantle ${ }^{20} \mathrm{Ne}$ concentration is fixed, and the calculated lower mantle ${ }^{36} \mathrm{Ar}$ concentration is inversely proportional to $\left(1+\delta_{\mathrm{SUB}}^{36}\right)$, so that 


$$
{ }^{20} \mathrm{C}_{\mathrm{P}} /{ }^{36} \mathrm{C}_{\mathrm{P}}=3.2\left(1+\delta_{\text {SUB }}^{36}\right)
$$

The minimum value for ${ }^{20} \mathrm{C}_{\mathrm{P}} /{ }^{36} \mathrm{C}_{\mathrm{P}}$ is 3.2 , which is much greater than the the atmospheric value of 0.52 and is within the range of meteorite compositions with 'solar' $\mathrm{Ne}$ isotope compositions (see ref. 32). The ${ }^{20} \mathrm{C}_{\mathrm{P}} / /^{36} \mathrm{C}_{\mathrm{P}}$ ratio is equal to the 'solar' ratio of $27^{56}$ for $\delta_{\mathrm{SUB}}^{36}=7.4$. This corresponds to $\mathrm{X}_{36}=\delta_{\mathrm{SUB}}^{36} /\left(1+\delta_{\mathrm{SUB}}^{36}\right) \approx 0.9$, where $\mathrm{X}_{36}$ is the fraction of ${ }^{36} \mathrm{Ar}$ in the upper mantle that is derived from subduction.

The calculated lower mantle ${ }^{36} \mathrm{Ar} /{ }^{130} \mathrm{Xe}$ ratio is dependent upon $\delta_{\mathrm{SUB}}^{130}$ and $\delta_{\mathrm{SUB}}^{36}$, neither of which can be independently constrained. An equation for ${ }^{36} \mathrm{C}_{\mathrm{P}} /{ }^{130} \mathrm{C}_{\mathrm{P}}$ can be obtained from eqn. 2 for ${ }^{36} \mathrm{Ar}$ and ${ }^{130} \mathrm{Xe}$ (see ref. 32 for derivation), so that

$$
\frac{{ }^{130} \mathrm{C}_{\mathrm{P}}}{{ }^{36} \mathrm{C}_{\mathrm{P}}}=\left[\delta_{\text {SUB }}^{130}\left(430-{ }^{36} \mathrm{C}_{\text {SUB }} /{ }^{130} \mathrm{C}_{\text {SUB }}\right)+530\right]^{-1}
$$

In the case of no subduction $\left(\delta_{\mathrm{SUB}}^{130}=0\right),{ }^{130} \mathrm{C}_{\mathrm{P}} /{ }^{36} \mathrm{C}_{\mathrm{P}}=1.9 \times 10^{-3}$. This value is similar to the meteoritic 'planetary' ratio of $1.56 \times 10^{-3}$ (ref. 59) and substantially greater than either the atmospheric ratio of $1.12 \times 10^{-4}$ or the 'solar' value of $1.67 \times 10^{-6}$ (ref. 51). For the calculated ${ }^{130} \mathrm{C}_{\mathrm{P}}{ }^{36} \mathrm{C}_{\mathrm{P}}$ to be much less than $1.9 \times 10^{-3}$, two conditions must be met in eqn. 15 . Firstly, the ratio of ${ }^{36} \mathrm{C}_{\mathrm{SuB}} /{ }^{130} \mathrm{C}_{\mathrm{SuB}}$ must be less than 430 , which requires that ${ }^{36} \mathrm{C}_{\text {SUB }} /{ }^{130} \mathrm{C}_{\text {SUB }}<0.05\left({ }^{36} \mathrm{Ar} /{ }^{130} \mathrm{Xe}\right)_{\mathrm{ATM}}$, so that atmospheric $\mathrm{Xe}$ in subducted materials must be substantially enriched with respect to atmospheric Ar. This is not unreasonable. Secondly, $\delta_{\mathrm{SUB}}^{130}$ must be large. In figure $5,{ }^{130} \mathrm{C}_{\mathrm{P}} /{ }^{36} \mathrm{C}_{\mathrm{P}}$ is plotted against $\mathrm{X}_{130}$ (the fraction of ${ }^{130} \mathrm{Xe}$ in D that is derived from subduction ) where $\mathrm{X}_{36}=\delta_{\mathrm{SUB}}^{36} /\left(1+\delta_{\mathrm{SUB}}^{36}\right)$, for various values of ${ }^{36} \mathrm{C}_{\mathrm{SUB}} /{ }^{130} \mathrm{C}_{\mathrm{SUB}}$ normalized to the atmospheric ratio. For the calculated ratio of ${ }^{130} \mathrm{Xe} /{ }^{36} \mathrm{Ar}$ in the lower mantle to be as low as that of the atmosphere requires $\mathrm{X}_{130}>0.95$, regardless of the ratio of Xe/Ar in subducted materials. This is extreme, and it appears that the ${ }^{130} \mathrm{Xe} /{ }^{36} \mathrm{Ar}$ ratio of the lower mantle is higher than the atmospheric ratio, and possibly as high as the chondritic ratio.

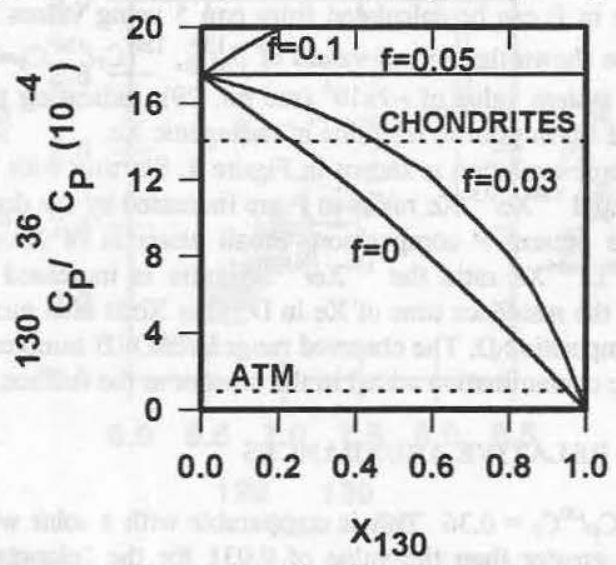

Figure 5. The calculated ${ }^{130} \mathrm{Xe} /{ }^{36} \mathrm{Ar}$ ratio in $\mathrm{P}$ plotted against $\mathrm{X}_{130}$, the fraction of ${ }^{130} \mathrm{Xe}$ in $\mathrm{D}$ derived from subduction. Curves are shown for different efficiencies of subduction of $\mathrm{Ar}$ relative to $\mathrm{Xe}$, with $\mathrm{f}=\left({ }^{36} \mathrm{Ar} /{ }^{130} \mathrm{Xe}\right)_{\mathrm{SuB}} /\left({ }^{36} \mathrm{Ar} /{ }^{130} \mathrm{Xe}\right)_{\mathrm{ATM}}$. The ${ }^{130} \mathrm{Xe} /{ }^{36} \mathrm{Ar}$ ratio calculated for $\mathrm{P}$ is similar to the $\mathrm{CI}$ chondrite value for $\mathrm{X}_{130}<0.5$, and approaches the atmospheric value only for $X_{137}>0.95$.
The rare gas abundance pattern in $\mathrm{D}$ is more constrained than that of the lower mantle, since the ${ }^{36} \mathrm{Ar}$ calculated concentration in $\mathrm{D}$ is not dependent upon the fraction of upper mantle Ar derived from subduction (eqn 11). The calculated ${ }^{130} \mathrm{Xe}$ concentration in D changes by a maximum of $10 \%$ for different values of $\mathrm{X}_{130}{ }^{\text {ref } 29}$. It follows that ${ }^{20} \mathrm{C}_{\mathrm{D}} /{ }^{36} \mathrm{C}_{\mathrm{D}}=3.2$ and ${ }^{130} \mathrm{C}_{\mathrm{D}} /{ }^{36} \mathrm{C}_{\mathrm{D}} \approx 1.7 \times 10^{-3}$. These values are both an order of magnitude greater than the corresponding ratios for the atmosphere of 0.52 and $1.1 \times 10^{-4}$, respectively. This pattern of $\mathrm{Ne}$ and Xe enrichment over $\mathrm{Ar}$ with respect to the atmospheric rare gas relative abundances is consistent with measured MORB abundance patterns $^{18}$. Since the upper mantle 
rare gas abundance pattern is not sensitive to the amount of $\mathrm{Ar}$ and Xe subduction, it cannot be used to infer the amount of rare gas subduction or further constrain the lower mantle abundance pattern.

\section{FORMATION OF THE ATMOSPHERE}

The model treats the atmosphere as an independent reservoir with rare gas isotopes that are distinct from both mantle reservoirs. This is a direct consequence of the observation of distinct ${ }^{20} \mathrm{Ne} /{ }^{22} \mathrm{Ne}$ ratios in the mantle, and storage of ${ }^{129} \mathrm{Xe}$ and ${ }^{136} \mathrm{Xe}$ excesses in the lower mantle. Since the model begins with observations of the upper mantle and interaction between $\mathrm{D}$ and $\mathrm{P}$, there are no initial assumptions about the atmosphere in relation to the solid Earth. However, from consideration of atmospheric and mantle rare gas systematics, requirements for both rare gas loss from the Earth and rare gas acquisition can be obtained. The correlation of ${ }^{136} \mathrm{Xe} /{ }^{130} \mathrm{Xe}$ with ${ }^{129} \mathrm{Xe} /{ }^{130} \mathrm{Xe}$ in MORB samples ${ }^{11}$ indicates that the ${ }^{129} \mathrm{I} /{ }^{244} \mathrm{Pu}$ ratio of the lower mantle at the time of its formation was $\sim 10^{-4}$ of the early solar system value ${ }^{29}$. An I depletion of $10^{-2}$ has been inferred from degree of depletion of elements with volatile affinities ${ }^{61}$, so that the additional depletion of $10^{-2}$ reflects early losses of daughter ${ }^{129} \mathrm{Xe}$ over $\sim 6$ half-lives of ${ }^{129} \mathrm{Xe}$, or $\sim 10^{8} \mathrm{yr}$. This implies a I-Xe 'age' of the Earth of $\sim 10^{8}$ years younger than that of meteorite parent bodies of $4.55 \mathrm{Ga}$. It has been argued that the abundance of atmospheric radiogenic $\mathrm{Xe}$ implies a similar young age $\mathrm{e}^{36,37}$. Such losses up to $4.45 \mathrm{Ga}$ may have occurred from the fully-formed Earth or from proto-planetary materials of a late-forming Earth.

Losses of radiogenic Xe would necessarily be accompanied by losses of nonradiogenic rare gases. Losses may have occurred from the proto-Earth atmosphere during accretion ${ }^{20}$ and during impact of a Mars-size body to produce the moon ${ }^{21,22}$. The coincidence of the I-Xe timescale with the young ${ }^{207} \mathrm{~Pb}-{ }^{206} \mathrm{~Pb}$ age of the Earth and moon ${ }^{62-64}$ suggests that $\mathrm{Pb} / \mathrm{U}$ fractionation may have occurred during these events.

Most of the nonradiogenic Xe in the atmosphere must be derived from late-accreted material that is more Xe-rich than the lower mantle to generate an atmospheric ${ }^{136} \mathrm{Xe}^{130} \mathrm{Xe}$ ratio that is lower than that of the mantle $\mathrm{e}^{29}$. The calculated concentrations of rare gases in the lower mantle are fully consistent with the hypothesis that a large proportion of rare gases presently in the atmosphere must be from late accreted material. If the Earth originally had a uniform concentration of rare gases, then degassing of the upper mantle would have provided only a small fraction of the atmosphere inventory. The remainder of the atmospheric nonradiogenic rare gases must be derived from material with a higher concentration of rare gases than the lower mantle. The source of the atmosphere cannot be from the late addition of $\mathrm{CI}$ chondrite material, which has Xe that is too radiogenic. A source rich in Xe relative to I is required, and our preferred source is cometary material (see also ref. 65 and 66). This material must arrive after catastrophic loss of rare gases from the Earth's atmosphere during the moon-forming impact.

The Xe in the earth's atmosphere has been isotopically fractionated with regard to any anticipated source. It is possible that this fractionation resulted from losses on the late-accreting bodies $^{67}$ or by hydrodynamic loss from the Earth's atmosphere after accretion ${ }^{23,24}$. This process may also be responsible for the lower atmospheric Xe/Ar ratio than that of the solid Earth (see ref. 24). Such losses which occurred from the Earth to generate the present isotopic composition must have followed late accretion of rare gases. Fractionating loss processes may also be responsible for the lower atmospheric ${ }^{20} \mathrm{Ne} /{ }^{22} \mathrm{Ne}$ ratio than the mantle, although this can also be explained by late accretion of $\mathrm{Ne}$ with a lower average ${ }^{20} \mathrm{Ne} /{ }^{22} \mathrm{Ne}$ ratio. The possible relationships between the inferred loss of the "original" volatile inventory along with radiogenic Xe and the inferred loss responsible for the present observed isotopic fractionation and abundance patterns in the atmosphere are open questions.

The above conclusions regarding the evolution of the terrestrial atmosphere are compatible with current understanding of planetary processes ${ }^{68}$. Comparisons can also be drawn with the rare gas systematics of Mars. It has been argued that Mars has lost a substantial proportion of its volatile inventory based upon such factors as geomorphological evidence for abundant water that is no longer observed $^{69}$ and the low abundances of rare gases and other volatiles measured in the martian 
atmosphere by Viking ${ }^{70,71}$. Evidence of SNC meteorites, which have been attributed to Mars, also support the idea of Mars as a planet that accreted rich in volatiles, but which has suffered substantial atmospheric loss ${ }^{72}$. Pepin ${ }^{24}$ and $\mathrm{Zahnle}^{73}$ have reviewed the martian data and possible evolutionary processes. Measurements from the SNC meteorites have obtained precise determinations of the isotopic compositions of martian rare gases ${ }^{\text {e.g } 74}$. Xe isotopes are fractionated with respect to solar or $\mathrm{CI}$ chondrite $\mathrm{Xe}$ compositions, and this has been attributed to fractionation during loss from the atmosphere by hydrodynamic escape ${ }^{24}$. These losses have resulted in a decoupling of the current atmosphere from the interior.

In summary, early losses of gases have occurred from both planets. The Earth appears to show late accretion of gas-rich material that has supplied volatiles to the terrestrial atmosphere. However, both planets have atmospheres that evolved by large losses that have caused isotopic and elemental fractionations, as well as by additions of radiogenic nuclides from the interior.

\section{ACKNOWLEDGMENTS}

This work was supported by NASA NAGW3337 and DOE DE-FG-88ER13851. This is Division Contribution 5477(874). Reviews by M. Honda and D. Patterson are particularly appreciated.

\section{REFERENCES}

1. H. Brown, in The Atmospheres of the Earth and Planets (ed. G. P. Kuiper), (Univ. of Chicago Press, IL, 1952) 258.

2. W. B. Clarke, M. A. Beg and H. Craig, Earth Planet. Sci. Lett. $\underline{6}, 213$ (1969).

3. B. A. Mamyrin, I. N. Tolstikhin, G. S. Anufriev, and I. L. Kamanskiy, Dokl. Akad. Nauk S.S.S.R. 184, 1197 (1969).

4. A. Krylov, B. A. Mamyrin, L. A. Khabarin, T. I. Mazina, and Yu. I. Silin, Geokhim. $\underline{8}, 1220$ (1974).

5. J. E. Lupton and H. Craig, Earth Planet. Sci. Lett. 26, 133 (1975).

6. H. Craig and J. E. Lupton, Earth Planet. Sci. Lett. $\underline{31}, 369$ (1976).

7. R. J. Poreda and F. Radicati di Brozolo, Earth Planet. Sci. Lett. 69,277 (1984).

8. P.Sarda, T. Staudacher, and C. J. Allègre, Earth Planet. Sci. Lett. 91, 73 (1988).

9. M. Honda, J. H. Reynolds, E. Roedder, and S. Epstein, J. Geophys. Res. 92,12507 (1987).

10. W. A. Butler, P. M. Jeffery, J. H. Reynolds, and G. J. Wasserburg, J. Geophys. Res. 68, 3283 (1963).

11. T. Staudacher and C. J. Allègre, Earth Planet. Sci. Lett. 60 , 389 (1982).

12. K. K. Turekian, Geochim. Cosmochim. Acta 117, 37 (1959).

13. M. Ozima, Geochim. Cosmochim. Acta 39,1127 (1975).

14. R. Hart, J. Dymond, and L. Hogan, Nature 278, 156 (1979).

15. S. B. Jacobsen and G. J. Wasserburg, J. Geophys. Res. $\underline{84}, 7411$ (1979).

16. R. K. O'Nions, N. M. Evensen, and P. J. Hamilton, J. Geophys. Res. 84, 6091 (1979).

17. C. J. Allègre, T. Staudacher, P. Sarda, and M. Kurz, Nature 303, 762 (1983).

18. C. J. Allègre, T. Staudacher, and P. Sarda, Earth Planet. Sci. Lett. 81, 127 (1986).

19. D. Porcelli, J. O. H. Stone, and R. K. O'Nions, Lunar Planet. Sci. XVII, 674 (1986).

20. A. G. W. Cameron, Icarus $\underline{56}, 195$ (1983).

21. W. K. Hartmann and D. Davis, Icarus 24, 504 (1975).

22. A. G. W. Cameron and W. R. Ward, Lunar Sci. Z, 120 (1976).

23. D. M. Hunten, R. O. Pepin, and J. C. G. Walker, Icarus $\underline{69}, 532$ (1987).

24. R. O. Pepin, Icarus 92,2 (1991).

25. R. K. O'Nions and E. R. Oxburgh, Nature 306,429 (1983).

26. S. J. G. Galer and R. K. O'Nions, Nature $\underline{316}, 778$ (1985).

27. L. H. Kellogg and G. J. Wasserburg, Earth Planet. Sci. Lett. 99, 276 (1990).

28. D. B. Patterson, M. Honda, and I. McDougall, Geophys. Res. Lett. 17, 705 (1990).

29. D. Porcelli and G. J. Wasserburg, Geochim. Cosmochim. Acta, in press (1995).

30. D. Porcelli and G. J. Wasserburg, Lunar Planet. Sci. XXV, 1097 (1994)

31. D. Porcelli and G. J. Wasserburg, Abstr. 8th ICOG Conf. 255 (1994).

32. D. Porcelli and G. J. Wasserburg, Geochim. Cosmochim. Acta, submitted (1995).

33. R. K. O'Nions, S. R. Carter, N. M. Evensen, and P. J. Hamilton, The Sea 7, 49 (1981).

34. K. P. Jochum, A. W. Hoffmann, E. Ito, H. M. Seufert, and W. M. White, Nature 306, 431 (1983). 
35. G. B. Hudson, B. M. Kennedy, F. A. Podosek, and C. M. Hohenberg, Proc. 19th Lunar Planet. Sci. Conf. 547 (1989).

36. G. W. Wetherill, Ann. Rev. Nuclear Sci. 25, 283 (1975).

37. R. O. Pepin and D. Phinney, unpublished manuscript (1978).

38. M. D. Kurz, W. J. Jenkins, and S. R. Hart, Nature 297, 43 (1982).

39. W. Rison and H. Craig, Earth Planet. Sci. Lett. 66, 407 (1983).

40. J. H. Reynolds, U. Frick, J. M. Niel, and D. L. Phinney, Geochim. Cosmochim. Acta 42 , 1775 (1978).

41. T. K. Kyser and W. Rison, J. Geophys. Res. 87, 5611 (1982).

42. B. Marty, Earth Planet. Sci. Lett. 94,45 (1989).

43. M. Honda, I. McDougall, and D. Patterson, Lithos 30, 257 (1993).

44. K. Farley and R. J. Poreda, Earth Planet. Sci. Lett. 114, 325 (1993).

45. H. Hiyagon, M. Ozima, B. Marty, S. Zashu, and H. Sakai, Geochim. Cosmochim. Acta 56, 1301 (1992).

46. M. Honda, I. McDougall, D. Patterson, A. Doulgeris, and D. Clague, Nature 349, 149 (1991).

47. M. Honda, I. McDougall, D. Patterson, A. Doulgeris, and D. Clague, Geochim. Cosmochim. Acta 57, 859 (1993).

48. R. J. Poreda and K. A. Farley, Earth Planet. Sci. Lett. 113, 129 (1992).

49. D. C. Black, Geochim. Cosmochim. Acta 36, 347 (1972).

50. J.-P. Benkert, H. Baur, P. Signer, and R. Wieler, J. Geophys. Res. $\underline{98}, 13147$ (1993).

51. P. Eberhardt, J. Geiss, H. Graf, N. Grogler, M. D. Mendia, M. Morgeli, H. Schwaller, and A. Stettler, Proc. Lunar Sci Conf. 2, 1821 (1972).

52. J. Geiss, F. Buehler, H. Cerutti, P. Eberhardt, and C. H. Filleaux, Apollo 16 Prelim. Sci. Rep. NASA SP$\underline{315}, 14-1$ (1972).

53. M. Ozima and S. Zashu, Earth Planet. Sci. Lett. 62, 24 (1983).

54. P. Sarda, T. Staudacher, and C. J. Allègre, Earth Planet. Sci. Lett. 72 , 357 (1985).

55. T. Staudacher, P. Sarda, S. H. Richardson, C. J. Allègre, I. Sagna, and L. M. Dmitriev, Earth Planet. Sci. Lett. 96,119 (1989).

56. A. G. W. Cameron, Space Sci. Rev. 15, 121 (1973).

57. G. Igarashi, Ph.D. Dissertation, Geophysical Institute, Univ. of Tokyo, (1988).

58. M.W. Caffee, G.B. Hudson, C. Velsko, E.C. Alexander Jr., G.R. Huss, and A.R. Chivas, Lunar Planet. Sci. XIX, 154 (1988).

59. E. Mazor, D. Heymann, and E. Anders, Geochim. Cosmochim. Acta 34, 781 (1970).

60. R. K. O'Nions and I. N. Tolstikhin, Earth Planet. Sci. Lett. 124, 131 (1994).

61. H. Wanke, Phil. Trans. R. Soc. Lond. A303, 287 (1981).

62. F. Tera and G. J. Wasserburg, Proc. 5th Lunar Conf. 2 , 1571 (1974).

63. J. S. Stacey and J. D. Kramers, Earth Planet. Sci. Lett. 26, 207 (1975).

64. A. J. Gancarz and G. J. Wasserburg, Geochim. Cosmochim. Acta 41, 1283 (1977).

65. T. Owen, A. Bar-Nun, and I. Kleinfeld, Nature 358, 43 (1992).

66. M. Ozima and N. Wada, Nature $\underline{361}, 693(1993)$ and T. Owen and A. Bar-Nun, Nature $\underline{361}, 693(1993)$.

67. M. Ozima and K. Zahnle, Geochem. J. 27, 185 (1993).

68. D. Porcelli and G.J. Wasserburg, Lunar Planet. Sci. XXVI, 1129 (1995).

69. M. Carr, Icarus 68,187 (1986).

70. A.O. Nier and M.B. McElroy, J. Geophys. Res. 82,4341 (1977).

71. T. Owen, K. Biemann, D.R. Rushneck, J.E. Biller, D.W. Howarth, and A.L. Lafleur, J. Geophys. Res. $\underline{82}$, 4635 (1977).

72. G. Dreibus and H. Wanke, Meteoritics 20,367 (1985).

73. K. Zahnle, J. Geophys. Res. $\underline{98}, 10899$.

74. T.D. Swindle, M.W. Caffee, and C.M. Hohenberg, Geochim. Cosmochim. Acta $\underline{50}, 1001$ (1986). 